\title{
No association between human herpesvirus 6 reactivation and cryptococcosis in human immunodeficiency virus-infected patients
}

Human herpesvirus 6 (HHV-6) is a part of the virus subfamily betaherpes. A recent in vitro study suggested that HHV-6 may dysregulate monocyte-mediated anticryptococcal defences with an overall procryptococcus result (Cermelli et al., 2006). Briefly, co-cultures of THP1/JJHAN cell lines were tested for anti-cryptococcal activity by c.f.u. inhibition assay. THP1/ JJHANmock and THP1/JJHAN $\mathrm{HHV}_{\text {-6 }}$ cocultures were exposed to Cryptococcus neoformans for 2, 3, 4 and $6 \mathrm{~h}$. The cocultures showed negative levels of anticryptococcal activity that were more marked for THP1/JJHAN $\mathrm{HHV}_{\text {- }}$ at $6 \mathrm{~h}$. The results demonstrated that macrophages exposed to HHV-6 have reduced anticryptococcal activity.

Cryptococcosis is a major cause of opportunistic infections in Cambodian human immunodeficiency virus (HIV)infected patients with severe immunodepression (Chhin et al., 2004; Senya et al., 2003). Indeed, the prevalence of cryptococcal infection among HIVinfected patients with a CD $4^{+}$count $<200$ cells $\mathrm{mm}^{-3}$ was $18.0 \%(59 / 327)$ in a recent Cambodian study (Micol et al., 2007).

The HHV-6 seroprevalence is up to $90 \%$ in children less than 2 years old in industrialized countries (Irving \& Cunningham, 1990). No data are available concerning the HHV-6 seroprevalence in the Cambodian population. However, in Thailand the seroprevalence of HHV- 6 was $88.1 \%(185 / 210)$ in children under 12 years old (Bhattarakosol et al., 2001). HHV-6 reactivation has been observed in HIV-infected individuals (Astriti et al., 2006; Qavi et al., 1995). Thus, we compared the prevalence of HHV-6 reactivation among 53 cases of cryptococcal infection and 105 controls without cryptococcal infection to validate or not in vivo data obtained in vitro by Cermelli et al. (2006).

In 2007, stored sera (Institut Pasteur du Cambodge) were used for HHV-6 and cytomegalovirus (CMV) DNA detection by quantitative PCR. DNA was extracted from $200 \mu \mathrm{l}$ serum with the MagNA Pure Compact (Roche) following the MagNA Pure Compact nucleic acid isolation kit I protocol. We used the HHV-6 quantitative in-house PCR from the Virology Laboratory of the Pitié Salpêtrière Hospital (Paris, France) (Gautheret-Dejean et al., 2002). The CMV real-time PCR was conducted according to the protocol used in the Unite de Virologie of the Hôpital Necker-Enfants Malades since 2001 (Leruez-Ville et al., 2003). HHV-6 replication was defined as the presence of HHV-6 DNA in serum. Cryptococcal infection was defined by a positive cryptococcal polysaccharide agglutination test [in serum or cerebrospinal fluid (CSF)] and/or positive C. neoformans culture (blood, CSF or urine), or positive India ink direct examination of CSF. Continuous variables were presented with their median and interquartile range (IQR). Variables were compared between groups using the Mann-Whitney $U$ test for continuous variables, and the chi-square or Fischer's exact test for categorical variables.

The median (IQR) age of patients was 34 years (31-37 years). The median CD4 ${ }^{+}$ count (IQR) was 14 cells $\mathrm{mm}^{-3}$ (6-32 cells $\left.\mathrm{mm}^{-3}\right)$. The two groups presented no difference in age (median 35 versus 34 years), gender (males/females $34 / 19$ versus $62 / 43$ ) and $\mathrm{CD}^{+}$count $\left[14\right.$ cells $\mathrm{mm}^{-3}$ (IQR 6-24 cells $\mathrm{mm}^{-3}$ ) versus 15 cells $\mathrm{mm}^{-3}$ (IQR 6-47 cells $\mathrm{mm}^{-3}$ )]. The prevalence of positive HHV-6 PCR was $3.8 \%(2 / 53)$ in the cryptococcal infection group and $0 \%$ in controls (Fisher exact test $P=0.1)$. The CMV DNAaemia prevalence was $56.6 \%(30 / 53)$ and $55.2 \%$ $(58 / 105)$ in cases and controls, respectively $(P=0.9)$. The viral loads of the two HHV-6 positive sera were high (5.4 and $6.0 \mathrm{log}$ copies $\mathrm{ml}^{-1}$ ) suggesting either reactivation with high replication or a possible chromosomal integration (Ward et al., 2006). In addition there was no more
CMV replication among patients with cryptococcal infection than among those without infection.

In conclusion, there was no in vivo association between HHV-6 replication and cryptococcal infection in Cambodian HIV-infected patients. Severely immunodepressed HIV-infected patients with HHV-6 or CMV DNA in their serum do not present an increased risk of developing cryptococcosis than appropriate controls.

\section{Acknowledgements}

The authors thank Anne Badrichani for scientific discussion about this manuscript and Dawn Gaither for reviewing the manuscript.

\section{Romain Micol, ${ }^{1}$ Philippe Buchy, ${ }^{2}$ Julie Galimand, ${ }^{1}$ Duong Veasna, ${ }^{2}$ Laurent Ferradini, ${ }^{3}$ Suna Balkan, ${ }^{4}$ Philippe Jean Guerin, 5 \\ Pierre-Régis Martin, ${ }^{6}$ Arnaud Fontanet, ${ }^{7}$ Olivier Lortholary, ${ }^{8}$ Christine Rouzioux ${ }^{1}$ and Marianne Leruez-Ville ${ }^{1}$}

${ }^{1}$ Unité de Virologie, Hôpital NeckerEnfants Malades, Université René Descartes, EA 36-20, Paris, France

${ }^{2}$ Unité de Virologie, Institut Pasteur du Cambodge, Phnom Penh, Cambodia

${ }^{3}$ Médecins Sans Frontières, Hôpital Préa Bath Norodom Sihanouk, Phnom Penh, Cambodia

${ }^{4}$ Médecins Sans Frontières, Paris, France ${ }^{5}$ Epicentre, Paris, France

${ }^{6}$ Médecins Du Monde, Hôpital Kosamak, Phnom Penh, Cambodia

${ }^{7}$ Unité d'Epidémiologie des Maladies Emergentes, Institut Pasteur, Paris, France

${ }^{8}$ Service des Maladies Infectieuses et Tropicales, Université René Descartes, Hôpital Necker-Enfants Malades, Centre d'Infectiologie Necker-Pasteur, Paris, France 
Correspondence: Romain Micol (romain.micol@gmail.com)

Astriti, M., Zeller, V., Boutolleau, D., GautheretDejean, A., Allen, G., Seilhean, D., Agut, H., Bricaire, F., Katlama, C. \& Bossi, P. (2006).

Fatal HHV-6 associated encephalitis in an HIV1 infected patient treated with cidofovir. J Infect 52, 237-242.

Bhattarakosol, P., Pancharoen, C. \&

Mekmullica, J. (2001). Seroprevalence of antihuman herpes virus-6 IgG antibody in children of Bangkok, Thailand. Southeast Asian J Trop Med Public Health 32, 143-147.

Cermelli, C., Cenacchi, V., Beretti, F., Pezzini, F., Luca, D. D. \& Blasi, E. (2006). Human

herpesvirus- 6 dysregulates monocyte-mediated anticryptococcal defences. J Med Microbiol 55, 695-702.

Chhin, S., Rozycki, G., Pugatch, D. \& Harwell, J. I. (2004). Aetiology of meningitis in HIV- infected patients in a referral hospital in Phnom Penh, Cambodia. Int J STD AIDS 15, 48-50.

Gautheret-Dejean, A., Manichanh, C., ThienAh-Koon, F., Fillet, A. M., Mangeney, N., Vidaud, M., Dhedin, N., Vernant, J. P. \& Agut, H. (2002). Development of a real-time polymerase chain reaction assay for the diagnosis of human herpesvirus- 6 infection and application to bone marrow transplant patients. J Virol Methods 100, 27-35.

Irving, W. L. \& Cunningham, A. L. (1990).

Serological diagnosis of infection with human herpesvirus type 6. BMJ 300, 156-159.

Leruez-Ville, M., Ouachee, M., Delarue, R., Sauget, A. S., Blanche, S., Buzyn, A. \& Rouzioux, C. (2003). Monitoring cytomegalovirus infection in adult and pediatric bone marrow transplant recipients by a realtime PCR assay performed with blood plasma. $J$ Clin Microbiol 41, 2040-2046.

Micol, R., Lortholary, O., Sar, B., Laureillard, D., Ngeth, C., Dousset, J. P., Chanroeun, H., Ferradini, L., Guerin, P. J. \& other authors
(2007). Prevalence, determinants of positivity, and clinical utility of cryptococcal antigenemia in Cambodian HIV-infected patients. J Acquir Immune Defic Syndr 45, 555-559.

Qavi, H. B., Green, M. T., Lewis, D. E., Hollinger, F. B., Pearson, G. \& Ablashi, D. V. (1995). HIV-1 and HHV-6 antigens and transcripts in retinas of patients with AIDS in the absence of human cytomegalovirus. Invest Ophthalmol Vis Sci 36, 2040-2047.

Senya, C., Mehta, A., Harwell, J. I., Pugatch, D., Flanigan, T. \& Mayer, K. H. (2003). Spectrum of opportunistic infections in hospitalized HIVinfected patients in Phnom Penh, Cambodia. Int J STD AIDS 14, 411-416.

Ward, K. N., Leong, H. N., Nacheva, E. P., Howard, J., Atkinson, C. E., Davies, N. W., Griffiths, P. D. \& Clark, D. A. (2006). Human herpesvirus 6 chromosomal integration in immunocompetent patients results in high levels of viral DNA in blood, sera, and hair follicles. $J$ Clin Microbiol 44, 1571-1574. 